\title{
Aligning ICCP Certification With The IS2002 Model Curriculum: A New International Standard
}

Lynn J. McKell (E-mail: ljm@email.byu.edu), Brigham Young University John H. Reynolds, Grand Valley State University

Herbert E. Longenecker, University of South Alabama Jeffrey P. Landry, University of South Alabama

\section{Introduction}

his is a progress report on actions to align vendor neutral certification for computing and Information Systems professionals with academic standards as codified by the IS2002 Model Curriculum.

As part of its "Certified Computing Professional" (CCP) certification program, the Institute for Certification of Computing Professionals (ICCP) offers a "Core" exam. This exam has been changed and modified periodically to reflect the state of the art in information systems technology and related disciplines.

Concurrently, in the early 1990's a task force of prominent academics continued their collaboration begun in 1982 and produced revised curriculum guidelines for undergraduate degree programs oriented to higher education in Information Systems - the first report is titled "IS'95: Guideline for Undergraduate IS Curriculum." (See Cougar, et. al., 1995) This highly referenced work has subsequently undergone multiple updates. (See Davis, et. al., 1997, and Gorgone, et. al., 2002). The most recent iteration of this genre, the "IS 2002 Model Curriculum and Guidelines for Undergraduate Degree programs in Information Systems" (IS2002) (Gorgone, et. al., 2002), was recently released for general discussion and use in academia.

Sponsoring organizations for the IS2002 Model Curriculum study and report include the Association for Computing Machinery (ACM), the Association for Information Systems (AIS), and the Association of Information Technology Professionals (AITP). Sessions at professional conferences hosted by these associations have on occasion focused on the various IS curriculum guidelines, on certification and on accreditation. One strong common thread of interest that ties all of these topics together is the need for individual assessment.

Growing primarily out of interaction at the 2002 Information Systems Educators Conference (ISECON) sponsored by the AITP Education Special Interest Group (EDSIG), in late 2002 Dr. John H. Reynolds (Grand Valley State University), ICCP Associate Director of Certification, and Drs. Herbert E. Longenecker and Jeffrey P. Landry (both from the University of South Alabama) formed a coalition to pursue development of an outcome assessment exam sufficiently robust to serve as the core exam for ICCP certifications, and an outcome assessment exam for students who have participated in a university curriculum based on the IS2002 Model Curriculum Guidelines - thus bringing into alignment two critical elements in support of a strong professional foundation for preparing people to serve in Information Systems related careers. I will refer to this exam as the IS2002 Core exam. This coalition has produced a beta version ${ }^{1}$ of such an assessment instrument, which has been tested in a number of venues. While the statistical analysis of this beta testing is yet to be reported, the purpose of this paper is to explain the basic outcome assessment exam development process, make academics and professionals aware of the ongoing development and through that awareness to begin building a coalition of "grass roots" acceptance for the IS2002 Model Curriculum and support for broad based outcome assessment and vendor neutral certification in the area of Information Systems.

\footnotetext{
${ }^{1}$ As of this time of writing, the IS2002 Core exam has not yet been presented to the ICCP board of directors for approval to use in the certification process, though it has had limited ICCP Certification Council evaluation with a positive initial review.
} 


\section{The Institute For Certification Of Computing Professionals (ICCP)}

The Institute for Certification of Computing Professionals (ICCP), based in Des Plaines, Illinois USA, was organized in 1973 by a coalition of professional societies and associations to deliver competency examinations and provide high quality vendor neutral certifications to professionals in computing related careers. The ICCP is governed by a board of directors whose seats are sponsored by the following professional associations:

1. $\mathrm{ACM}$

2. AITP

3. AWC

4. CIPS

5. DAMA

6. ISTE
Association for Computing Machinery

Association of Information Technology Professionals

Association for Women in Computing

Canadian Information Processing Society

Data Management Association

International Society for Technology in Education

The ICCP board of directors has the responsibility of establishing policies and procedures.

Currently, the ICCP offers two levels of certification based on a portfolio of over twenty examinations. I will first identify the examinations and how they are developed; then I will explain how these are used in the two levels of certification. The portfolio of examinations (including the number of questions and time limit) are:

Common Exam for both certifications (110 questions, 90 minutes)

1. Core Examination

$\underline{\text { Language Examinations (66 questions, } 60 \text { minutes) }}$

1. Basic

2. Cobol

3. $\mathrm{C}$

4. $\mathrm{C}++$

5. Pascal

6. RPG400

7. Visual Basic

(8.) (Java - in development)

Specialty Examinations (110 questions, 90 minutes)

1. Advanced Programming

2. Business Information Systems

3. Data Resources Management

4. Internetworking and Communication

5. Management

6. Microcomputing and Networks

7. Object Oriented Analysis and Design

8. Office Information Systems

9. Software Engineering

10. Systems Development

11. Systems Programming

12. Systems Security

13. Web Development 


\section{New Examinations}

The list of examinations is growing as new exams are developed and brought on line in response to industry needs. There is also a program for retiring examinations which have outlived their usefulness. The examinations are developed, managed and updated under the direction of the ICCP Certification Council, which has responsibility to insure that exams meet all appropriate standards of rigor, accuracy, effectiveness and currency. A pool of examination questions is maintained along with a history of utilization and related psychometric data useful in evaluating the efficacy of all test items.

New examinations are typically developed by a collaborating team of industry professionals and academic professors. New examinations are beta tested by students and industry professionals. These results are used to benchmark the exams and insure that the level of difficulty correlates well with norms expected at different levels of career development.

Typically, in each examination besides the graded questions, approximately $10 \%$ of the questions are new and are not graded; they are being evaluated by collecting psychometric data which will be used to determine if they qualify to be rotated into the examination. For each examination the ICCP Certification Council maintains a large pool of questions to draw from in updating examinations.

\section{ICCP Certifications}

As previously mentioned, the ICCP administers two industry certifications under the supervision of the Board of Directors. While in the past there have been other certifications offered (e.g. CDP and CSP), currently these have been consolidated into the following two certifications:

1. Associate Computing Professional (ACP) for those who are appropriately trained, but are at an industry entry level with little direct experience, and

2. Certified Computing Professional (CCP) for well established seasoned information technology professionals.

The requirements for each of these certifications include:

ACP: Pass the Core Examination at the 50\% level or higher

Pass any Language or Specialty Examination at the 50\% level or higher.

Ascribe to a professional code of ethics.

CCP: Pass the Core Examination at the 70\% level or higher

Pass two Specialty Examinations at the $70 \%$ level or higher.

(Note: two language examinations at $70 \%$ can substitute for one specialty examination)

Have 5 years of documented IT industry related experience.

(Note: a degree in an IT related field can substitute for 2 years of experience.)

Ascribe to a professional code of ethics.

It should be noted the current "Core" examination covers a broad range of basic concepts and skills which would be expected of competent professionals in computer and information systems careers. Furthermore, any examinee who passes a language or specialty exam at $70 \%$ or higher can obtain a "Certificate of Competency" for that language or specialty. Many "certified" professionals (i.e. ACP or CCP) and non-certified professionals take ICCP examinations to obtain a certificate of competency in a computer language or specialization.

The CCP is typically obtained by someone who has graduated with a major field of study in computing or information systems from an accredited institution (university or college) who also has been working for a minimum of several years (longer if they do not have a related terminal degree) on appropriately related projects. Besides the 
education and experience, applicants for the CCP designation must take at least three certification examinations: the core, plus two specialty exams (from a roster of over a dozen exams).

The ACP is commonly aspired to by those who are in the final stage of completing their education for entry into a computing/information system career path. They typically have not worked long as a full time IT career professional if at all, and they are expected to pursue the CCP after acquiring the required professional experience.

\section{Development Of The Core Assessment Exam From The Is2002 Model Curriculum}

For more than a decade, an academic task force has been active to define the body of knowledge for pedagogical purposes in preparing an appropriate curriculum for students desiring to enter information systems careers. These efforts have resulted in several iterations of an undergraduate model curriculum including IS'95, IS'97, and the latest incarnation recently released - the IS2002 Model Curriculum. These academic efforts have met with wide acceptance for several reasons: 1) the Model Curriculum has been developed by respected educators who are well known for both solid research and effective pedagogy; and 2) they have used a strong theoretical foundation drawn from a statistical analysis of industry needs reflected in employment ads for developing the curriculum. While a full explanation of this development process will be done in other publications (See Landry, et. al., 2003), the following brief description may prove useful:

Data was gathered from several job listing publications from a variety of locations throughout the United States. These were analyzed for key words related to specific skills. Using statistical methods, this data was distilled to identify a set of skills and sub-skills which are required by graduating students as they enter the job market. These skills/sub-skills were correlated with the IS2002 model curriculum learning units and the related learning unit goals to create exit objectives. These exit objectives were used as the basis for writing appropriate assessment examination questions.

In order to accomplish writing the exit objectives and the examination questions, faculty from some twenty US colleges and universities were recruited to participate in a workshop in early February held at the University of South Alabama. Faculty were divided into teams approximately correlating individual areas of specialization with high level course modules from the IS2002 Model Curriculum. This workshop and subsequent follow-up efforts resulted in the creation of 230 exit objectives and 303 examination questions. From this an examination consisting of 100 questions was prepared and administered as follows:

1. Approximately 171 examinees took the IS2002 Core examination at the AITP 2002 National Collegiate Conference (NCC) held at Purdue University, West Lafayette, Indiana USA. These examinees were primarily students majoring in Information Systems or a related program. It is judged that most were upperclassmen in their senior year (on the verge of graduation) or in their late junior year, though some were less mature in their education program, thus, many of these students were at the point of entering their professional careers.

2. Most of the schools who sent faculty members to participate in the February workshop also administered the IS2002 Core Examination to students at their institutions. Approximately 500 students were involved from the nearly twenty participating institutions.

Follow-up workshops with faculty representatives from the twenty coalition schools will be held in Summer, 2003 and Summer, 2004 to refine the IS2002 Core exam, and to extend the process to other related areas of assessment.

\section{Preliminary Results:}

The data from participating schools has not yet been fully analyzed. However, preliminary results from the National Collegiate Conference are as follows (See ICCP website, 2003): 


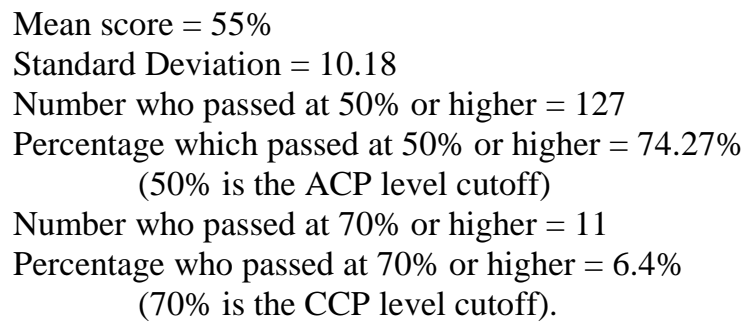

Further analysis will use a larger sample and will analyze the correlation of pass rates with education level. It is also important to realize that NCC students tend to be a cut above their peers and are generally good students. Preliminary indications are that the IS2002 Core examination benchmarks about where it should be, passing a good percentage of new graduates at the entry level (50\%), but filtering out (failing) most of them at the professional level (70\%). It is desirable that students have a few years to mature and learn from experience before being able to pass at the professional level.

\section{Conclusion}

The ICCP - IS2002 Model Curriculum Task Force coalition has successfully produced an assessment examination based on a strong theoretical foundation correlated with a prescribed curriculum based on actual needs in the job market. Initial beta tests encouragingly suggest:

1. The level of the IS assessment exam is appropriate to measure entry level skills,

2. The exam may be a suitable Core exam for vendor neutral certification purposes, and

3. This exam based on a strong theoretical foundation reflecting the real body of knowledge needed in the work place sets a new International Standard for assessing individual competence, whether for educational program outcome assessment or for professional certification.

Note on Authors: Lynn J. McKell is Chairman of the ICCP New Examination Committee, a member of the ICCP Certification Council, and Vice President of the ICCP Education Foundation. John H. Reynolds is Associate Director of the ICCP Certification Council and is a principle member of the coalition team developing the IS2002 Core examination. Herbert E. Longenecker is a principle member of the IS2002 Model Curriculum task force and a principle member of the coalition team developing the IS2002 Core examination. Jeffrey P. Landry is a principle member of the coalition team developing the IS2002 Core examination.

\section{References}

1. Cougar, J.D., G.B. Davis, D.G. Dologite, D.L. Feinstein, J.T. Gorgone, M. Jenkins, G.M. Kasper, J.C. Little, H.E. Longenecker Jr., J.S. Valachie, "IS'95: Guideline for Undergraduate IS Curriculum," MIS Quarterly (19:3), 1995, pp. 341-360.

2. Davis, G.B., J.T. Gorgone, J.D. Cougar, D.L. Feinstein, H.E. Longenecker Jr., "IS'97 Model Curriculum and Guidelines for Undergraduate Degree Programs in Information Systems," ACM, New York and AITP (formerly DPMA), Park Ridge, IL, 1997.

3. Gorgone, J.T., G.B. Davis, J.S. Valacich, H. Topi, D.L. Feinstein, H.E. Longenecker Jr., "IS 2002 Model Curriculum and Guidelines for Undergraduate Degree Programs in Information Systems (Draft)," ACM, new York, NY, AIS, and AITP (formerly DPMA), Park Ridge, IL, 2002

4. ICCP website: www.iccp.org/iccpnew/aitp-ncc2003.html, 2003.

5. Landry, J.P, J.H. Reynolds, H.E. Longenecker, Jr., "Assessing Readiness Of IS Majors To Enter The Job Market: An IS Competency Exam Based On The Model Curriculum," (forthcoming - accepted for presentation at the 2003 AMCIS conference.), 2003. 
Notes 